\title{
North Atlantic atmospheric regimes and winter extremes in the Iberian peninsula
}

\author{
M. J. OrtizBeviá ${ }^{1}$, E. SánchezGómez ${ }^{2}$, and F. J. Alvarez-García ${ }^{1}$ \\ ${ }^{1}$ Department of Physics, University of Alcalá, Alcalá de Henares, Madrid, Spain \\ ${ }^{2}$ Climate Modelling and Global Change Group, CERFACS, CNRS, 31057 Toulouse cedex 01, France
}

Received: 2 April 2010 - Revised: 29 December 2010 - Accepted: 12 February 2011 - Published: 25 March 2011

\begin{abstract}
In this study, we assess the relationships between North Atlantic scale atmospheric regimes and extremes of precipitation and minimum temperature in the Iberian peninsula for an extended (DJFM) winter season. As found in previous studies, large scale atmospheric regimes are well represented in climate simulations while the extreme atmospheric variability is not. The relationship between some of these atmospheric regimes and the probability of occurrence of extreme values in simulations of present day climatic variability is validated here with daily observations at 68 meteorological stations all over the Iberian peninsula. Therefore, the possible changes in the probability of occurrence of winter extremes of minimum temperature and precipitation are obtained by projecting the changes in the probability of occurrence of the winter atmospheric regimes. The trends in the frequency of the observed large scale patterns give an indication of what can be expected in the next decades. For the long term (in a century), the changes are obtained directly from the comparison of the frequencies of the atmospheric regimes in the scenario simulations with those of the historical period. The projections obtained in this way are tested for consistency with the results obtained by comparing the changes in the extremes threshold values in the scenario with those of the historical simulations. The results point to a future with less precipitation extreme events and less minimum temperature extreme events in winter in the westerly central part of the Iberian peninsula.
\end{abstract}

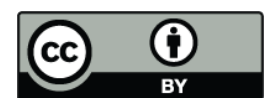

Correspondence to: M. J. OrtizBeviá (ortizbeviamr@gmail.com)

\section{Introduction}

Meteorological extreme events have important environmental and socio-economic impacts (SánchezGómez and Terray, 2005). Climate simulations performed with atmospheric or coupled General Circulation Models (GCM), represent some variables reasonably well, like the temperature at $850 \mathrm{hPa}$ or the geopotential height at $500 \mathrm{hPa}$. On the other hand, the simulations have shortcomings in the representation of some variables like precipitation or the occurrence of extreme events (Meehl et al., 2000). Therefore, they can not provide direct information on their evolution in the climate of the future. In order to obtain a more satisfactory representation of those variables or of extreme events, several studies proposed the use of an interface, either dynamical (for instance, Regional Climate Models, RCM) or statistical. Along these lines, Sánchez et al. (2004), for instance, used a RCM to study the evolution of extremes in the Mediterranean Region. They found significant negative changes in the precipitation decile in some areas in the southeast and the east of Spain. Significant increases in the minimum temperature (Tmin) decile for most of Spain have been found in a complete review paper using seven RCM (Beniston et al., 2007).

Previous works have established the relationship between atmospheric regimes and global extremes in some regions of the Northern Hemisphere (Robertson and Ghil, 1999; Plaut and Simmonet, 2001; Yiou and Nogaj, 2004). These studies show how atmospheric regimes influence some extreme event characteristics, as in the case of persistent blocking events, or the heat (cold) waves in the northern European summer (winter). In some cases, this relationship can be used for downscaling purposes (Boé et al., 2006). It offers also a potential for predictability, as the extreme event occurrences have been associated with transitions between weather

Published by Copernicus Publications on behalf of the European Geosciences Union. 
regimes (SánchezGómez and Terray, 2005). Transitions are in turn conditioned by the phase of an intra-seasonal oscillation in the European-Mediterranean sector (SánchezGómez et al., 2008). Large scale Atmospheric Regimes (hereinafter LAR) are preferred states of the circulation, characterised, among other properties, by its persistence, recurrence and stationarity. They are usually identified by applying classification techniques on a large number of daily $500 \mathrm{hPa}$ geopotential height maps. The $500 \mathrm{hPa}$ geopotential height and, therefore, atmospheric regimes, is a variable reasonably well represented in the climate simulations performed with atmospheric GCMs. In contrast, these simulations have shortcomings in the representation of some variables like precipitation or the occurrence of extreme events (Meehl et al., 2000). The objective of this study is to establish a connection between weather regimes and the probability of occurrence of extremes in the Iberian peninsula in winter and, thereby to estimate how this variability could be modified in the climate of the future, with a modified atmospheric composition. Once this relationship is established, we estimate the possible modifications in the future frequency of extremes from the changes in the occurrence of the large scale patterns. Trends in the evolution of the observed weather regimes could give an indication for the immediate future (one or two decades), while differences in the weather regime frequencies between scenario and historical period will point to the evolution once the anthropogenic climate change has stabilized.

Recent observational analysis has already noticed some of these changes in the intensity and in the frequency of extreme events. In the case of Spain, Prieto et al. (2004) reported increasing trends in the percentile value and decreasing trends in the number of extremes in historical records of minimum temperatures for the last part of the twentieth century. Similar trends are found by Rodriguez-Puebla et al. (2010) for the whole Iberian peninsula. In the case of extreme winter precipitation, decreasing trends for most of Spain and increasing trends along the Mediterranean coast were detected by García et al. (2007). Also for the Spanish region, Queralt et al. (2009) found only a weak connection between the trends in extreme values and the circulation types (10 Grosswetterlagen, GWL) while they detected a strong connection between trends in extreme values and those of the snow cover. On the other hand, van den Besselaar et al. (2010) established a significant relationship between $27 \mathrm{GWL}$ and extremes of temperature in the whole European sector. However, conclusions of this last work for Spain are not straightforward, the spatial coverage there being poor. Concerning the North Atlantic sector, a trend of the North Atlantic Oscillation toward its positive phase has been detected by Osborn (2004), corresponding to a decrease in surface pressure over the Artic and an increase over the subtropical North Atlantic. In the case of Blocking, a strong decreasing (4.5\%/decade) trend was found in the same sector (centred in Greenland) for winter (DJF), that changed to a weak positive trend in spring (MAM) (Croci-Maspoli et al., 2007).
The methodology applied in the present study relies on the assumption that the relationship between LAR and extremes would still be valid in a warmer climate (Wilby et al., 2004). Although this is a plausible hypothesis, this methodology has its limitations (Najac et al., 2009). Other procedures, like downscaling studies using dynamical models, do not seem more reliable, given the current representation of extremes in simulations of "state of the art" regional models. For that reason downscaling studies often assess the plausibility of their conclusions against those obtained by a direct determination on the scenario simulations (Boé et al., 2006). This is the procedure that we will also follow here.

The outline of the paper is as follows: Data are presented and the methodology followed is explained in Sect. 2. Results are described in Sect. 3 and discussed in Sect. 4.

\section{Data and methods}

The LAR patterns were identified from the field of daily anomalies of the geopotential height at $500 \mathrm{hPa}$ (hereafter Z500) in the North Atlantic sector obtained from the ERA40 reanalysis (Uppala et al., 2004) of daily maps, for an extended winter season (1 December through 31 March) of each year during the period 1958-2001. The anomalies were filtered, removing the variability associated with periods shorter than 10 days, and then expanded in terms of their empirical orthogonal functions (EOF). The variability of the field reconstructed with the first 10 EOF ( $90 \%$ of the filtered field) was classified using a k-mean clustering procedure (Michelangeli et al., 1995). The first four clusters retained roughly explain a $60 \%$ of the variance of the filtered field.

The future evolution of climate is estimated from daily minimum temperature and precipitation data from climate simulations under present and future conditions. The present climate data were extracted from three simulations performed at MeteoFrance with the Arpege model (Dequé et al., 1994). The model set up for the present climate simulations has an irregular grid, with approximately $50 \mathrm{~km}$ resolution over the Iberian peninsula, and was integrated for the period 1950-1999, with boundary conditions from a simulation with the coupled Arpege-ORCA global model. The data for the future climate come from two simulations performed with the same model under conditions corresponding to the scenario A1B for the period 2100-2149 (greenhouse gases concentrations fixed to the 2100 levels, Gibelin and Dequé, 2003). For the classification of the simulated daily maps, the centroids of the LAR determined from ERA-40 are used as existing clusters. Each map is aggregated to one of the clusters by a discriminating algorithm based by its distance to each of the centroids.

To validate the relationship between large-scale atmospheric patterns and extreme meteorological events in the Iberian peninsula, we use two data fields of daily 
observations of Tmin and precipitation at 68 meteorological stations (65 in Spain and 3 in Portugal). The Spanish observations were kindly supplied by the Spanish Meteorological Agency (AEMAT), while the Portuguese time series were obtained from the ECAC database (Klein Tank et al., 2002). They cover the period of the ERA-40 reanalysis (1958-2002). These data have been tested according to the guidelines in Aguilar et al. (2003) and only required slight modifications to pass several statistical homogeneity tests. The missing data at each station amount to less than $4 \%$ of the entire length of the record and the maximum number of missing days in a given month never exceeded 7\%. However, the variability of northern Spain is undersampled, due to the fact that few meteorological records there meet those quality requirements. Thereafter, winter time series were extracted, with the days corresponding to winter months as defined above (DJFM).

Extremes are identified from the time series (observed or simulated) as those values with probability of occurrence of $10 \%$ or lower. That is those outside the range between the upper and the lower decile value. At each station the original time series is ordered and the upper and lower deciles are determined. We then estimate the probability of the observation corresponding to the upper or lower decile of the LAR of a specific order in the original data. The changes of this probability for the upper or for the lower decile are pooled together and the value obtained in this way is a measure of the changes in the probability of the extreme values associated to the first, second, etc. LAR. That is, let $d_{\mathrm{u}}^{i}$ and $d_{1}^{i}$ be the upper and lower decile value, respectively, of the time series of the observations associated to a given LAR $i$, and let $d_{\mathrm{u}}$ and $d_{1}$ be the upper and lower decile value of the time series of all the observations. We consider that if, for a certain LAR, the probability of $d_{\mathrm{u}}^{i}$ or the probability of $d_{1}^{i}$ is increased (that is $d_{\mathrm{u}}^{i}<d_{\mathrm{u}}$ or $\left.d_{1}^{i}>d_{1}\right)$, the tail of the distribution of the observations will contain less extremes associated with this LAR than to some other LAR. Therefore, this LAR is associated with a decrease in the probability of extremes. The statistical significance is assessed with a Monte Carlo procedure as specified in Kondrashov et al. (2004). The data are repeatedly permuted, obtaining a new classification that preserves the length of the weather episodes. For these permuted time series, the changes in the probability of occurrence are estimated, as in the case of the original time series (observed or simulated), from the changes in the exceedance probability of the first (or second, etc.) LAR decile value estimated from the segregated time series with respect to the probability of the pooled time series.

The trends in the frequency of occurrence of each of the weather types were also used to estimate the evolution of climate in the next decades. Because some of these tendencies have not the required level of statistical significance, a second estimation was attempted, in another data field with a larger sample size. Trends of the same variable were also deter- mined from the 59 winters (1948-2007) of the Z500 anomalies obtained from the NCEP-NCAR Reanalysis (Kistler et al., 2001), that were previously classified with the methodology detailed for the simulations.

The LAR frequencies evolution in the climate of the future are determined using the LAR classification in the scenario simulations. Confidence limits were estimated with Monte Carlo techniques similar to the ones used to establish the significance of the extreme values. We compare them with the LAR frequencies distribution of the historical simulations.

We test the consistency of the projections obtained by the method detailed above for the future evolution of climate with those obtained through direct computation. In the case of the climate of the future, the decile values of the variables under study calculated directly from the scenario simulations, are compared with those obtained from the historical simulations. Upper and lower deciles are considered in the case of the Tmin, while only upper deciles are taken into account in the case of the precipitations.

\section{Results}

Four LAR were identified in the North Atlantic sector as in Vautard (1990). Their spatial patterns in winter are depicted in Fig. 1. In the Blocking (BL) pattern, there is a strong anticyclone over Scandinavia, in the Atlantic Ridge (AR) pattern the anticyclone is anchored in the mid-Atlantic. The zonal (ZO) regime presents the atmospheric conditions of the positive phase of the North Atlantic Oscillation (NAO+), while the Greenland anticyclone (GA) pattern reflects the negative conditions of the Oscillation (NAO-). The percentage of winter frequency of these weather regimes in the Z500 dataset of ERA-40 reanalysis is also given in Fig. 1. The $\mathrm{ZO}$ regime is the most frequent, followed by the BL and lastly, the AR and the GA regimes.

The dependence of the extreme values of the observed winter precipitations on the LAR, when statistically significant at the $90 \%$ confidence level, is presented in the two lower rows of Fig. 2. Increases in the values of the extremes are depicted by up-tipped, decreases by down-tipped triangles. During the BL situation (third row, left), the probability of extreme values of precipitation in the central and southerly parts of Iberia diminish, except for the Mediterranean coast, where they increase. During the ZO (third row, right) and the AR regimes (fourth row, left), the precipitation extremes decrease in the western part of Spain. In the ZO situation there is a contrast between the increases in the northern part of the Mediterranean coast and the decreases in the southeast, while in the AR regime there are increases on all the Mediterranean coasts. There is also a generalized increase in the precipitation extremes in the GA episodes, except for some regions of the Mediterranean coast.

The simulations capture the observed relationship between the extremes of precipitation and the LAR reasonably well in most of the domain (western and central part). However, on 

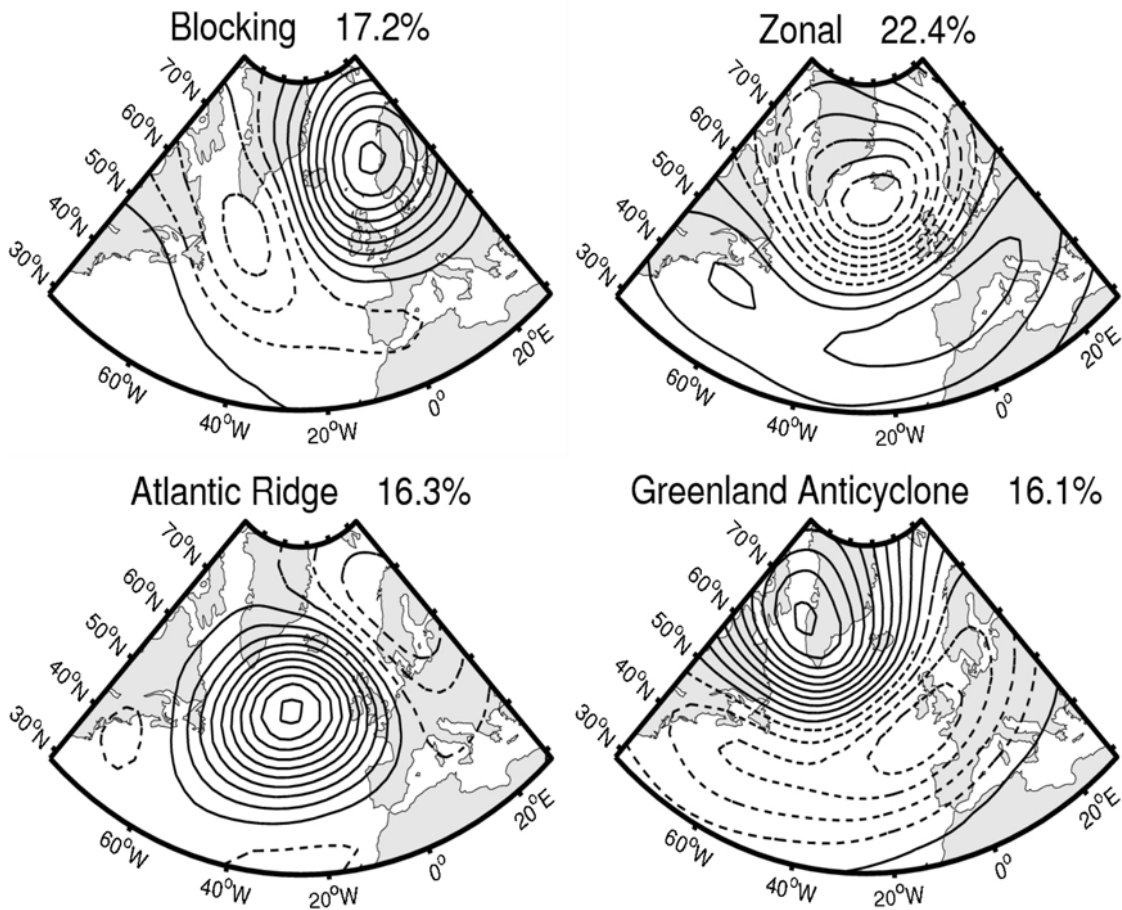

Fig. 1. The four atmospheric weather regimes (LAR). First row, Blocking (BL, left) and Zonal (ZO, right). Second row, Atlantic Ridge (AR, left) and Greenland Anticyclone (GA, right).

the Mediterranean coasts, the relationship between LAR patterns and precipitation (Millán et al., 2005b) is complicated and could not be captured by this simple scheme. The dependence of the extremes of the simulated precipitation are depicted in the upper two rows of Fig. 2. Increases are represented by up-tipped triangles, decreases by down-tipped. The grey scale to the right indicates the exceedance percentage. When the light shaded triangles are significant, an asterisk is added (for obvious reasons, dark shaded triangles are always significant). Both, $\mathrm{ZO}$ and $\mathrm{AR}$ are associated with a decrease of the extreme precipitations and GA with an increase of the same: the response is quite homogeneous, although there is some lack of significance in the south-east during the AR episodes. The effects of the BL relationship present a contrast between the Mediterranean coast (greater probability of extremes) and the rest of Spain.

In Fig. 3, we present the relationship between LAR and extremes of Tmin. In this case, increases in the decile absolute value indicate a greater probability of Tmin extreme values, and are represented as before by up-tipped triangles. The observed data show a coherent increase in the probability of extremes in the AR situation (Tmin decile absolute value grows) and likewise, a decrease of the same during the GA regime (milder minimum temperatures). The impact of these LAR on Tmin is well represented in the simulations. In the case of BL, there is also an increase in the probability of occurrence of extremes, but the observed dependence is weak (less than half of the stations are significant) and, therefore, hard to compare with the features of the simulated values that are significant only in the northern part of the peninsula.

Changes in the atmospheric regimes frequencies are estimated from the trends of the subseries of the reanalysed observations formed with the number of days of residence at each of the regimes per year. It seems reasonable to asume that in one or two decades, the tendencies found for the LAR frequencies will persist. Only two out of four tendencies identified from the LAR frequencies derived from ERA40 reanalysis ( 44 years) were found significant in a t-test: those of the ZO (increasing trend of $14 \%$ per decade) and the GA case (decreasing trend of $8 \%$ per decade) as represented in Fig. 4. The trends in the frequency of BL (positive) and AR (negative) were not found significant. Subsequently, the trends of the weather regime frequencies in the NCEPNCAR Z500 field were also estimated and are represented in Fig. 5. The trends found in the ZO and GA cases $(+12 \%$ per decade and $-12 \%$ per decade) are inside the confidence interval of the ones determined for the ERA- 40 reanalysis. Trends for the other two weather types (BL y AR) were also not significant in this case, even when the larger sample size provided conditions for a better statistical determination.

For the long-term future (a century ahead), the changes are estimated from changes in the probability of the LAR in the simulations: we compare the average number of days spent by the atmosphere in each of the four regimes in the historical simulations, with those spent in the scenario simulations. In Fig. 6, we represent the results of this estimation. 
BL
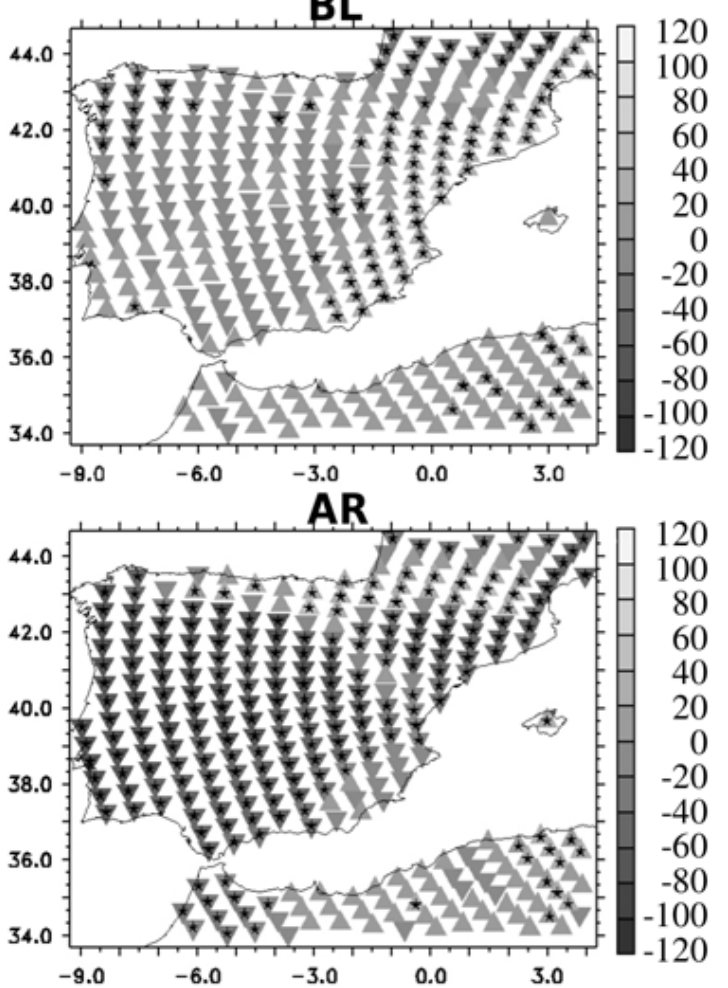

BL

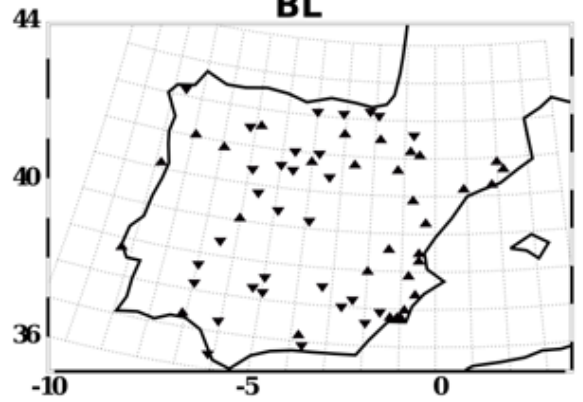

AR

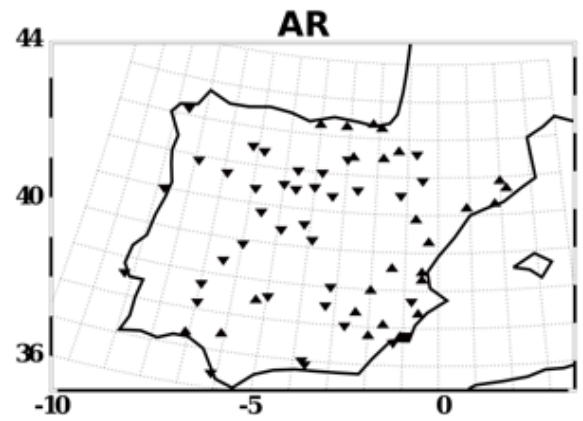

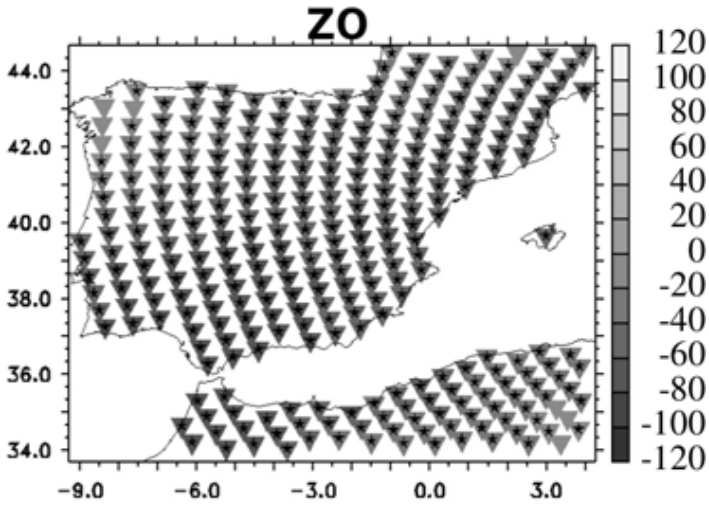

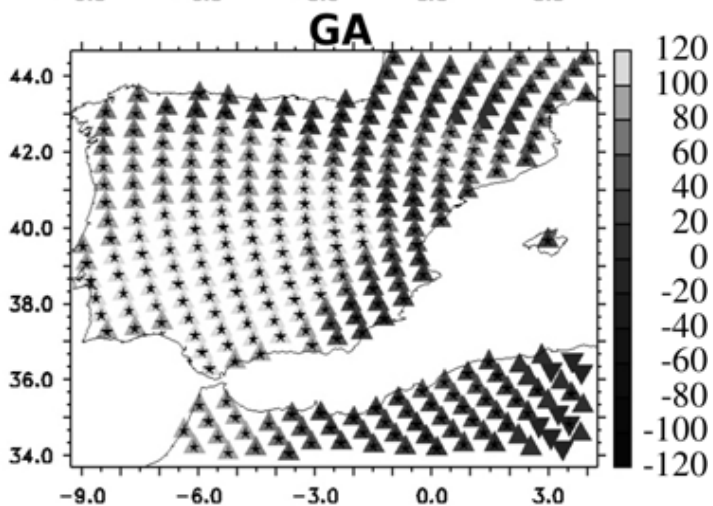

ZO

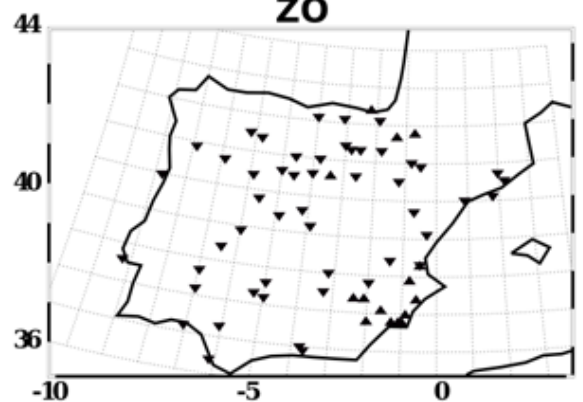

GA

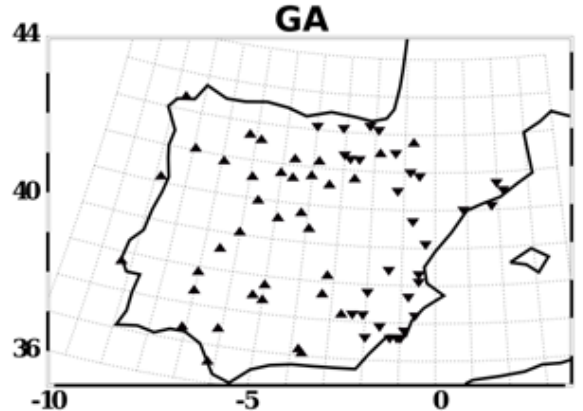

Fig. 2. Dependence of extreme values of precipitation on LAR. First and second row, the dependence in the historical simulations: first row, BL (left), ZO (right), second row, AR (left), GA (right). Up tipped triangles denote increases (with respect to the pooled decile values), downtipped triangles, decreases. Asterisk mark statistical significance, grey scale, percent of exceedance. Third and fourth row, the dependence in the observations: third row, BL (left), ZO (right), fourth row, AR (left), GA (right). Up-tipped triangles denote increases (with respect to the pooled decile values), down-tipped triangles, decreases. The grey scale to the right indicates the exceedance percentage. When the light shaded triangles are significant, an asterisk is added (dark shaded triangles are always significant). 

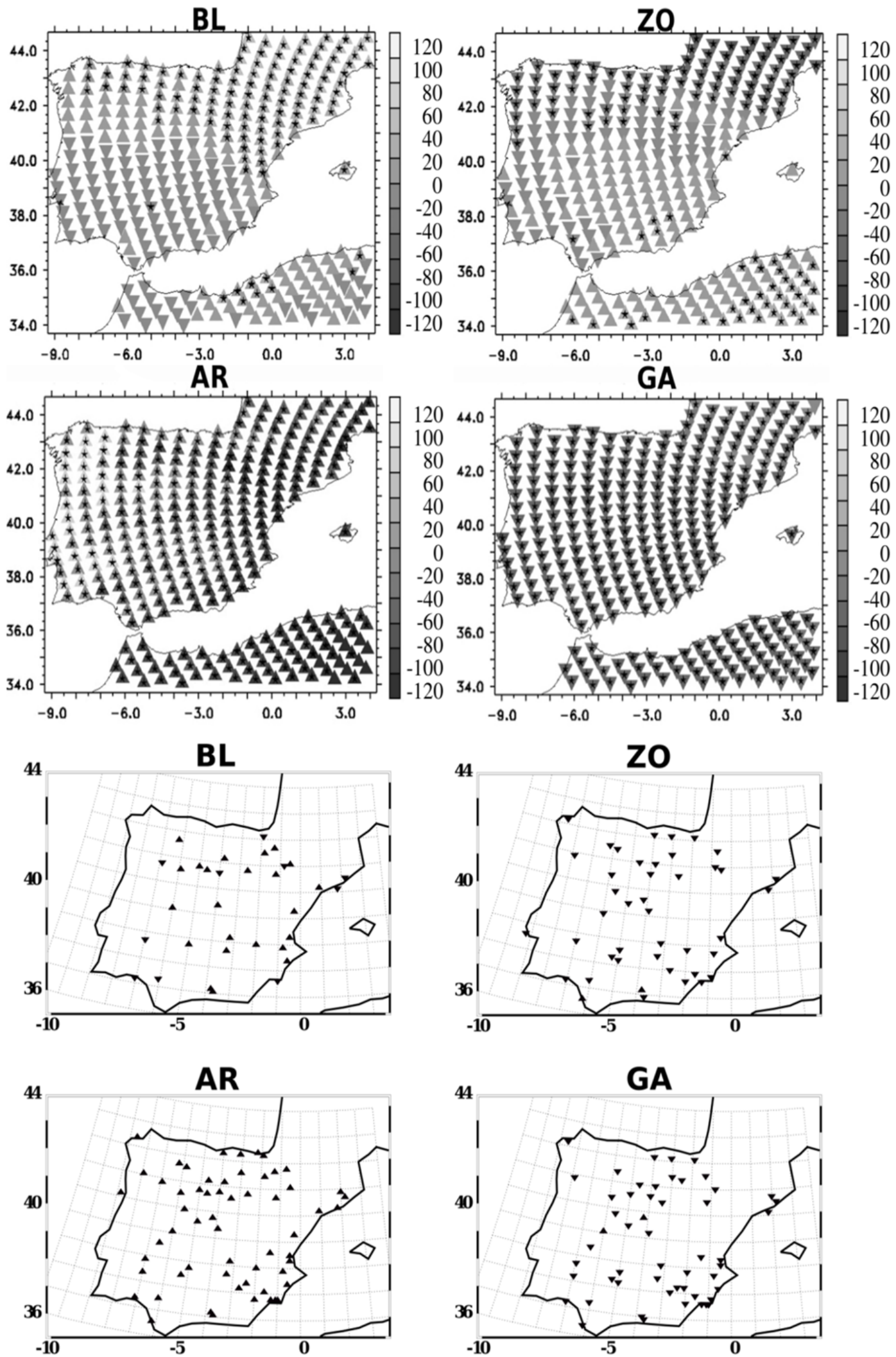

Fig. 3. Dependence of extreme values of minimum temperature on LAR. First and second row, the dependence in the historical simulations: first row, BL (left), ZO (right), second row, AR (left), GA (right). Symbols as previously. Third and fourth row, the dependence in the observations: third row, BL (left), ZO (right), fourth row, AR (left), GA (right). Up-tipped triangles denote increases (with respect to the pooled decile values), down-tipped triangles, decreases. 

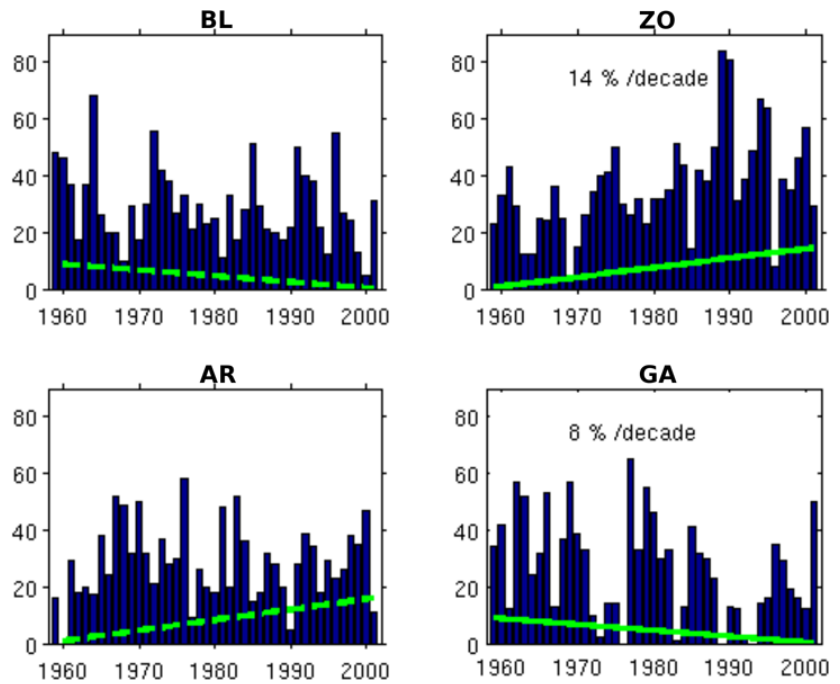

Fig. 4. Trends in the frequencies of observed LAR for the 45 years of the ERA-40 reanalysis (1958-2002). As before first row, BL (left), ZO (right), second row, AR (left), GA (right).
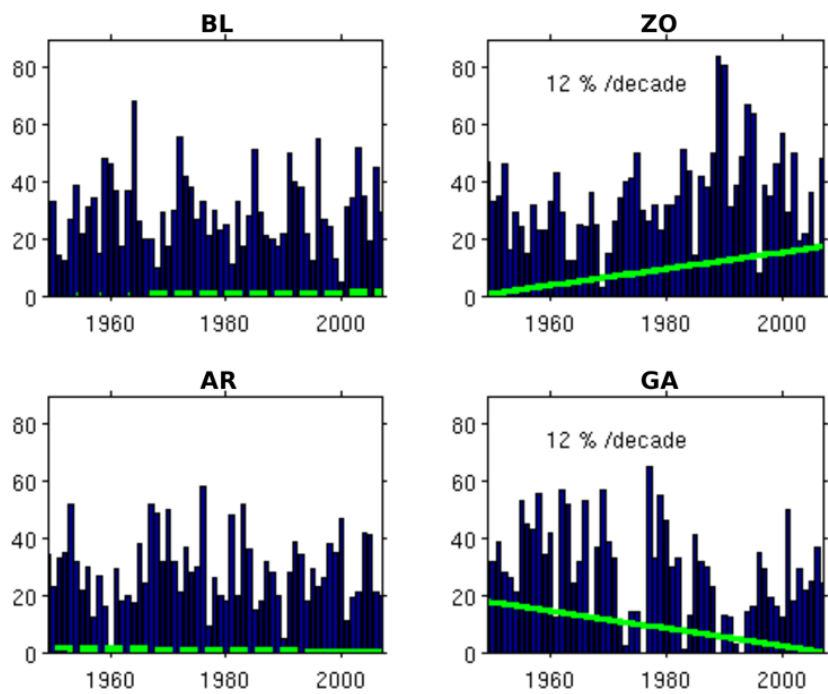

Fig. 5. Trends in the frequencies of observed LAR for the 59 years of the NCEP reanalysis (1948-2007). As before first row, BL (left), $\mathrm{ZO}$ (right), second row, AR (left), GA (right).

The increase in the number of $\mathrm{ZO}$ days is significant, as is the decrease in the number of GA days. The decrease in the frequency of the AR regime in the scenario simulations compared with historical, although considerable, is not statistically significant. Changes in the BL regime frequencies are less clear.

A further assessment was obtained from the direct comparison of the upper and lower decile values of the variables under study in the scenario simulations with those of the historical ones. The upper decile values of the precipitation in the historical simulations are represented in Fig. 7, top

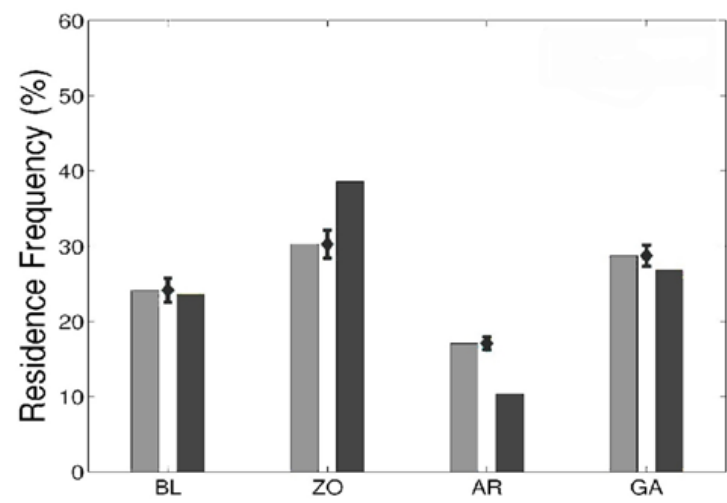

Fig. 6. Estimates of the changes in the frequencies of the LAR obtained from climate simulations. The bars, representing the frequencies of each of the four LAR types, are shaded light for the historical simulations and dark for the scenario ones. Confidence intervals obtained with a Monte Carlo procedure are depicted near the bars of the historical simulations.
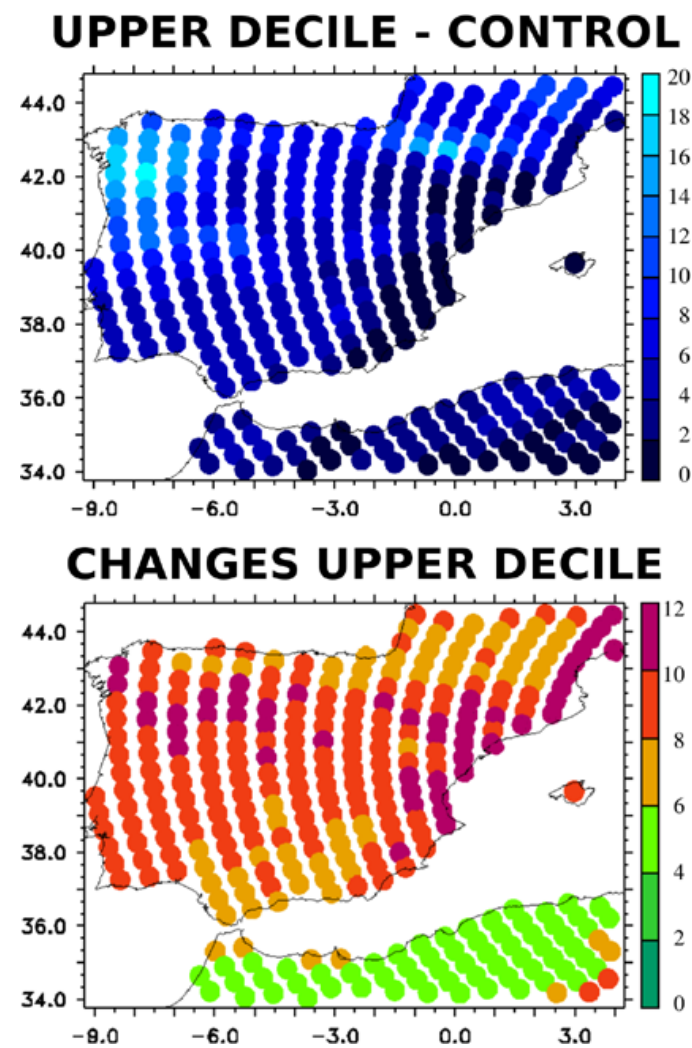

Fig. 7. In the top row the upper decile values of the precipitation (in $\mathrm{mm}$ day $^{-1}$ ), in the historical period simulations. In the bottom row, the percentages of exceedance of the historical upper decile values in the precipitations of the scenario simulations.

row. The percentages of exceedance of the historical upper decile values in the scenario simulations are represented in the same Fig. 7, bottom row. Upper decile values of the precipitation in the historical simulations are exceeded by 

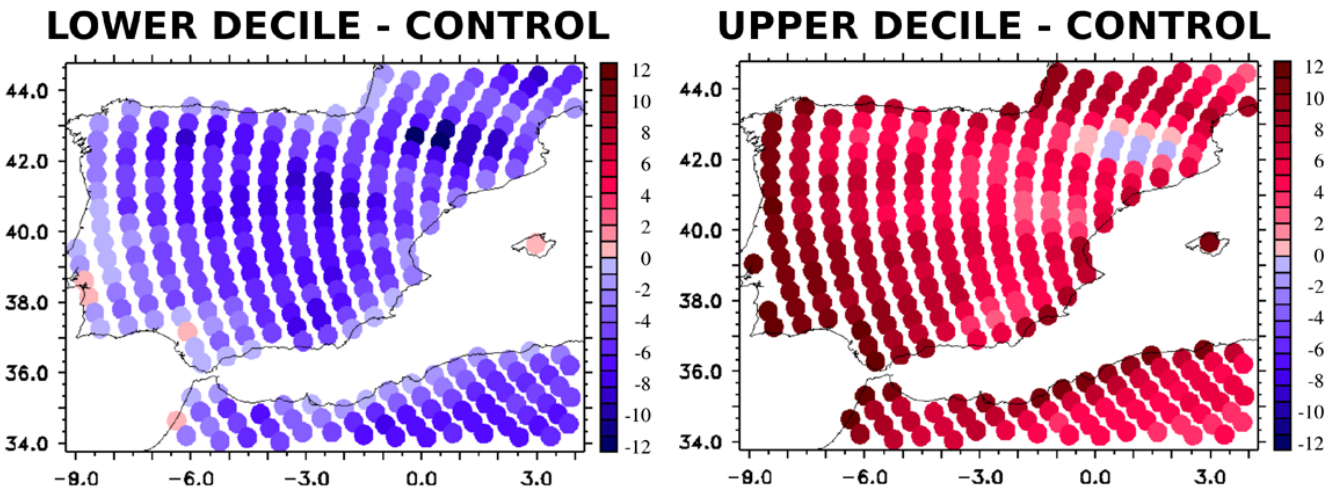

CHANGES LOWER DECILE

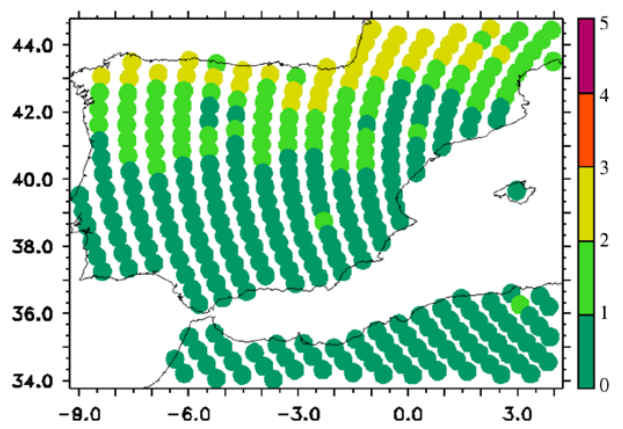

CHANGES UPPER DECILE

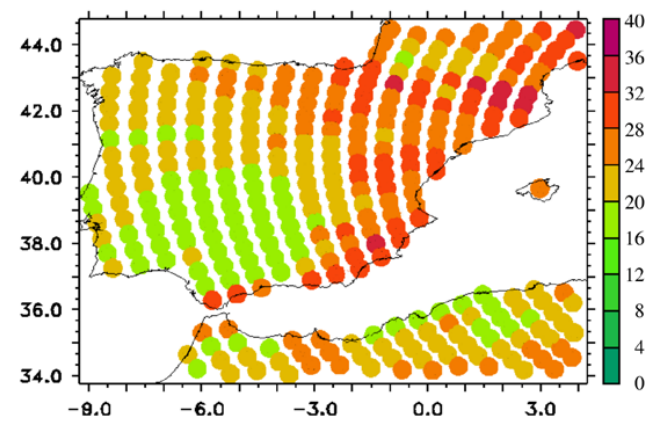

Fig. 8. In the top row, the lower decile values of the minimum temperature (left) and the upper decile values of the historical simulations (right). In the botton row, the percentages of exceedance of the historical lower decile values (left) and upper decile values (right) in the temperatures of the scenario simulations.

precipitation values in the scenario simulations in less than $10 \%$ of the cases and, thus, only in the northern part of the Mediterranean coast, and in northern Spain. In the case of the minimum temperatures (Fig. 8), the deciles of the historical simulations (in ${ }^{\circ} \mathrm{C}$ ) are represented in the top row and the percentages of exceedance of the scenario temperatures of the historical decile values, in the bottom row. The lower decile values are depicted to the left, the upper decile values to the right. The exceedance of the scenario temperatures of the lower decile values is less than $10 \%$ for all Spain. However, the historical upper decile values are exceeded in more than $35 \%$ of the cases, mainly along the Mediterranean coast. Altogether, this indicates that minimum temperatures could increase considerably in the climate of the future.

\section{Conclusion and discussion}

The main objective of this work was to estimate possible changes in extreme values of temperature and precipitation in the Iberian peninsula for an extended winter season. As found in previous studies, the extreme values of these variables are not well represented in simulations with atmospheric GCM while mean values of some large scale physical variables, like Z500, are. Large scale atmospheric patterns, that correspond to the four main weather regimes are iden- tified by this variable and, therefore, are satisfactorily represented in climate simulations. Changes in extreme values of minimum temperature and precipitation, in the next decade or so, and for the future, are obtained from the changes in the frequencies of LAR patterns. These are determined from the trends in the reanalysis fields and also from the changes of the scenario frequencies with respect to those of the historical period. The validity of our inferences of changes in the extremes, based on changes in the weather regime frequencies, therefore, relies on the validation of the relationships among those variables.

There is agreement between the increasing trends found for the frequency of the $\mathrm{ZO}$ regime in both datasets $(+14 \%$ per decade in ERA- 40 and $+12 \%$ per decade in NCEP), and the same can be said for the GA regime frequency $(-8 \%$ per decade in ERA-40 and $-12 \%$ per decade in NCEP), all of them significant at the $95 \%$ level. Those trends can be related to the trend towards its positive phase shown by the North Atlantic Oscillation (Osborn, 2004), that some studies have been found inconsistent with the internal variability of the basin (Osborn, 2004; Gillet et al., 2005). In both estimations, the one based in ERA-40 and the other from NCEP Reanalysis, the trends in the frequencies of occurrence of the other two weather types (BL and AR) are not found statistically significant. However, for the BL trends, there is an important 
difference in the risk II level (probability of being wrong accepting the null hypothesis): below $20 \%$ in the case of NCEP dataset and below $80 \%$ for ERA-40 (negative trend). In the case of the AR regime, the same risk II level goes from below $20 \%$ (NCEP) to less than $40 \%$ for ERA-40 (positive trend). These differences can be explained by differences in the influence of the interdecadal variability in each of the LAR.

The LAR identified in the observations are wellrepresented in the historical simulations. Therefore, we can estimate the changes one century ahead by comparing the frequencies in the scenario simulations with those for the historical period. The changes basically go in the same direction than the ones projected by the trends for the Zonal and GA regimes for the next future. However, the reduction in the occurrence of the AR regime is, not only important, but significant. In the case of BL, other studies (Sillmann and Croci-Maspoli, 2009) describe how the significant changes affect other variables than the frequency, like time-span or position of the centres of action. These will counteract one another to maintain the influence of blocking on most of Europe. But in the Iberian peninsula, due to the displacement of the centre of the negative anomalies from central to eastern Europe, this influence will be weakened.

In the case of precipitation, our results show, for most of the domain under study, a consistent relationship between extremes and weather regimes. For the central and western part of Spain, only one of the precipitation patterns associated exhibits a significant increase of extreme values (GA), and the tendency of this LAR is to be less frequent. The two procedures we have set up - the one based on the trends in the observed LAR frequencies and the other based in the comparison of those frequencies in the historical and scenario simulations - point to a decrease in the GA frequency. This indicates that extreme values of precipitation will be less probable in this region for the immediate as well as for the long-term future. Stations along the Mediterranean coast have a different behaviour: in the northeast, the ZO and GA patterns are associated with a decrease in the extreme events probability while AR and BL with an increase of the same. Millán et al. (2005a) show how some observed changes in the West Mediterranean region could be related to a decrease of the contribution of the precipitation of Atlantic origin, together with an increase in those of other kinds, i.e., convective. As the orography plays an important part in the feedback mechanisms set up by this modification, such effects might not be well captured by basin scale atmospheric patterns. Furthermore, the results of the direct estimation also support this conclusion.

In the case of minimum temperatures, the changes in probability in the western and interior Spain and in the Mediterranean coast have the same sign. Only for two of the regimes (GA and AR) the agreement between those changes in the observations and in the simulations under historical conditions can be considered good for all the domain, while for the other two (BL and $\mathrm{ZO}$ ) such agreement exists only in the northern part. In the case of the AR pattern, the trend found in the observations is not statistically significant. Therefore, only for the northern part of the domain the present study supports an evolution to less extreme minimum temperatures in the next decade or two. However, the important decrease in the frequency of the AR regime and the increase in the $\mathrm{ZO}$ one found in the scenario simulations with respect to the historical simulations points to a reduction in the probability of extreme minimum temperature under future conditions, for all the Iberian peninsula. This conclusion is further supported by the direct estimation.

Acknowledgements. The meteorological observations used in the present study were kindly supplied by the Spanish Meteorological Agency (AEMET). MeteoFrance is also acknowledged for the data of the simulations. This study was also supported by a grant of the CAM-UAH (2005/059) and by the EU-Contract GOCE-036961. Thanks are also due to the two anonymous reviewers of this paper.

Edited by: P. Lionello

Reviewed by: two anonymous referees

\section{References}

Aguilar, E., Auer, I., Brunet, M., Peterson, T. C., and Wieringa, J.: Guidelines on Climate metadata and homogeneization, WMO, WCDMP, 53, TD 1186, 2003.

Beniston, M., Stephenson, D., Christensen, O., Ferro, C., Frei, C., Goyette, S., Halsnaes, K., Holt, T., Jylhä, K., Koffi, B., Palutikof, J., Schöll, R., Semmler, T., and Woth, K.: Future extreme events in European climate: an exploration of regional climate model projections, Climatic Change, 81, 71-95, doi:10.1007/s10584006-9226-z, 2007.

Boé, J., Terray, L., Habets, F., and Martin, E.: A simple statistical-dynamical downscaling scheme based on weather types and conditional resampling, J. Geophys. Res., 111, D23106, doi:10.1029/2005JD006889, 2006.

Croci-Maspoli, M., Schwierz, C., and Davies, H. C.: A multifaceted climatology of atmospheric blocking and its recent linear trend, J. Climate, 20, 633-648, doi:10.1175/JCLI4029.1, 2007.

Dequé, J., Dreveton, C., Braun, A., and Carriolle, D.: The Arpege/IFS atmosphere model: A contribution to the French community climate modelling, Clim. Dynam., 10(4-5), 249266, doi:10.1007/BF00208992, 1994.

García, J. A., Gallego, M. C., Serrano, A., and Vaquero, J. M.: Trends in block-seasonal extreme rainfall over the Iberian Peninsula in the second half of the twentieth century, J. Climate, 20, 113-130, 2007.

Gibelin, A.-L. and Dequé, M.: Anthropogenic climate change over the Mediterranean region simulated by a global variable resolution model, Clim. Dynam., 20, 327-339, doi:10.1007/s00382002-0277-1, 2003.

Gillet, N. P., Allan, R. J., and Ansell, T. J.: Detection of external influence on sea level with a multi-model ensemble, Geophys. Res. Lett., 32, L19714, doi:10.1029/2005GL023640, 2005.

Kistler, R., Kalnay, E., Collins, W., Saha, S., White, G., Woollen, J., Chelliah, M., Ebisuzaki, W., Kanamitsu, M., Kousky, V., van der Dool, H., Jenne, R., and Fiorino, M.: The NCEP-NCAR 50-Year 
Reanalysis: Monthly Mean CD-ROM and Documentation, B. Am. Meteorol. Soc., 82, 247-267, 2001.

Klein Tank, M., Wijngaard, J., and van Englen, A.: Assessment of observed daily temperature and precipitation extremes, KNMI, De Bilt, the Netherlands, 36 pp., 2002.

Kondrashov, D., Ihde, K., and Ghil, M.: Weather regimes and preferred transition paths in a three level quasigeostrophic model, J. Atmos. Sci., 61, 568-587, 2004.

Meehl, G. A., Zwiers, F., Evans, J., Knutson, T., Mearns, L., and Whetton, P.: Trends in extreme weather and climate events: Issues related to modeling extremes in projection of future climate change, B. Am. Meteorol. Soc., 52, 1237-1256, 2000.

Michelangeli, P. R., Vautard, R., and Legras, B.: Weather regimes: recurrence and quasi stationarity, J. Atmos. Sci., 52, 1237-1256, 1995.

Millán, M. M., Estrela, M. J., Sanz, M. J., Mantilla, E., Martin, M., Pastor, F., Salvador, R., Vallejo, R., Alonso, L., Gangoiti, G., Ilardia, J. L., Navazo, M., Albizuri, A., Artinano, B., Ciccioli, P., Kallos, G., Carvalho, R. A., Andres, D., Hoff, A., Werhahn, J., Seufert, G., and Versino, B.: Climatic feedbacks and desertification: the Mediterranean Model, J. Climate, 18, 684-701, 2005a.

Millán, M. M., Estrela, M. J., and Miró, J.: Rainfall Components: Variability and spatial distribution in a Mediterranean Area (Valencia Region), J. Climate, 18, 2682-2705, 2005b.

Najac, J., Boé, J., and Terray, L.: A multi-model ensemble approach for assessment of climate change impact on surface winds in France, Clim. Dynam., 32(5), 615-634, doi:10.1007/s00382008-0440-4, 2008.

Osborn, T. J.: Simulating the winter North Atlantic Oscillation: the roles of internal variability and greenhouse forcing, Clim. Dynam., 22, 605-623, 2004.

Plaut, G. and Simmonet, E.: Large scale circulation classification, weather regimes and local climate over France, Clim. Res., 17, 303-324, 2001.

Prieto, L., García-Herrera, R., Díaz, J., Hernández, E., and del Teso, T.: Minimum extreme temperatures over Peninsular Spain, Global Planet. Change, 44(1-2), 59-71, doi:10.1016/j.gloplacha.2004.06.005, 2004.

Queralt, S., Hernández, E., Barriopedro, D., Gallego, D., Ribera, P., and Casanova, C.: North Atlantic Oscillation influence and weather types associated with winter total and extreme precipitation events in Spain, Atmos. Res., 94(4), 675683, doi:10.1016/j.atmosres.2009.09.005, 2009.

Robertson, A. W. and Ghil, M.: Large scale weather regimes and local climate over the western United States, J. Climate, 12, 1796$1813,1999$.
Rodriguez-Puebla, C., Encinas, A. H., García-Casado, L. A., and Nieto, S.: Trends in warm days and cold nights over the Iberian Peninsula: relationships to large scale variables, Climatic Change, 100, 667-684, 2010.

Sánchez, E., Gallardo, C., Gaertner, M. A., Arribas, A., and Castro, M.: Future climate extreme events in the Mediterranean simulated by a regional climate model: A first approach, Global Planet. Change, 44(1-4), 163-180, doi:10.1016/j.gloplacha.2004.06.010, 2004.

SánchezGómez, E. and Terray, L.: Large scale atmospheric dynamics and local intense precipitation episodes, Geophys. Res. Lett., 32, L24711, doi:10.1029/2005GL023990, 2005.

SánchezGómez, E., Terray, L., and Joly, B.: Intra-seasonal atmospheric variability and extreme precipitation events in the European-Mediterranean region, Geophys. Res. Lett., 35, L15708, doi:10.1029/2008GL034515, 2008.

Sillmann, J. and Croci-Maspoli, M.: Present and future atmospheric blocking and its impacts on European mean and extreme climate, Geophys. Res. Lett., 36, L10702, doi:10.1029/2009GL038259, 2009.

Uppala, S., Kallberg, P., Hernandez, A., Saarinen, S., Fiorino, M., Li, X., Onogi, K., Sokka, N., Andrae, U., and de Costa Bechtol, V.: ERA-40: ECNWF 45-year reanalysis of the global atmosphere and surface conditions 1957-1000, ECMWF Newsl., 101, 2-21, 2004.

Vautard, R.: Multiple weather regimes over the North Atlantic: Analysis of precursors and sucessors, J. Climate, 118, 20562081, 1990.

van den Besselaar, E. J. M., Klein Tank, A. M. G., and van der Schrier, G.: Influence of circulation types on temperature extremes in Europe, Theor. Appl. Climatol., 99, 431-439, doi:10.1007/s00704-009-0153-6, 2010.

Wilby, R. L., Charles, S. P., Zorita, E., Timbal, B., Whetton, P., and Mearns, L. O.: Guidelines for the use of Climate Scenarios Developped from Statistical Downscaling Methods, IPCC Task Group on Data and Scenario Support for Impact and Climate Analysis (TGICA), available at: http://ipcc-ddc.cru.uea.ac.uk, 2004

Yiou, P. and Nogaj, M.: Extreme climate events and weather regimes over the North Atlantic: When and where?, Geophys. Res. Lett., 31, L07202, doi:10.1029/2003GL019119, 2004. 